\title{
LESSON 28
}

\section{Letter 8}

PAPER: A5 (148 × $210 \mathrm{~mm})$.

MARGINS: Choose suitable margins.

TARGET TIME: 10 minutes.

Turn up 10 single lines before starting.

\section{Letter 9}

PAPER: A4.

MARGINS: Suitable.

TARGET TIME: 14 minutes.

Turn up 13 single lines before starting.

Letter 10

PAPER: A5 $(148 \times 210 \mathrm{~mm})$.

TARGET TIME: 10 minutes.

Turn up 10 single lines before starting.
Ref. JB/NY

To-day's date

Messrs. Cox \& Swift, 40 Dover Road, Deal. DE4 3AR

For the attention of the Accounts Department

Dear Sirs, with reference to your recent enquiry about your insurance premiums we have pleasure in submitting our revised quotation. (Paragraph) Mr. G. Hicken will be calling to see you next Tuesday to discuss any further problems you may have.

Yours faithfully, EVERSURE INSURANCE LTD.

J. Bowdler Actuary Enc.

Ref. VG/SM

To-day's date

The Headmaster, Coates Heath Comprehensive School,

Coates Heath, Shrewsbury. $\mathrm{CH} 7$ 9CC

For the attention of $\mathrm{Mr}$. B. Middleton

Dear sir, This company is, for the first time, producing books of a Commercial nature and we would like to take this opportunity of introducing them to you. As you know in the past we have built up a high reputation in the field of Classics. (Paragraph) Our new range of Commercial books will be available from next Easter and the topics covered will include Commerce, Accounts, Typing, both Gregg and Pitman Shorthand and ' $O$ ' level Economics. Printed in colour and fully illustrated we think these books are worthy of your consideration. (Paragraph) The enclosed literature gives details of the range, and inspection copies of all our new books are being sent to you. You should receive them in a day or two.

Yours faithfully, WILSON \& HEATH LTD. V. Gibbons Sales Manager Encs.

\section{Ref.PJ/IN Today's date.}

Miss Jewaifer Perry, 22 Lake Road, Bristol. QR 2 4ER JENNIFER Dear Miss Perry, Thank you for your application for the post of Audio-Typst in our Personuel Section. (Puragraph) Could you plesse attend for an interview on Monday next at 0930 hours? Intervieus will be held in the main offue block and on arrival you should ask for Miss Bridgen. (Paragraph) you are asked to be bring your C.S.E. Certificates with you. Yours truly, Pamela Jones

Secretary to Persound Officer 